\title{
06.1
}

\section{Фотолюминесценция композитов полиметилметакрилат / [(Zn,Cd)S : Mn,Cu,Eu]}

\author{
() В.П. Смагин, А.А. Исаева \\ Алтайский государственный университет, Барнаул, Россия \\ E-mail: smaginV@yandex.ru
}

Поступило в Редакцию 17 февраля 2021 г.

В окончательной редакции 30 апреля 2021 г.

Принято к публикации 12 мая 2021г.

\begin{abstract}
Методом возникающих реагентов в полимеризующейся среде метилметакрилата синтезированы наноразмерные структуры на основе сульфидов цинка и кадмия, легированных ионами $\mathrm{Mn}, \mathrm{Cu}$ и Еu. Широкополосная фотолюминесценция композиций связана с рекомбинационными процессами на уровнях дефектов полупроводниковых структур. Узкие полосы фотолюминесценции возникают при переходах электронов между уровнями энергии ионов $\mathrm{Eu}^{3+}$. Возбуждение фотолюминесценции происходит в результате межзонного перехода и переходов электронов на уровни дефектов структуры, а также при собственном поглощении и переносе энергии на уровни ионов $\mathrm{Eu}^{3+}$.
\end{abstract}

Ключевые слова: полупроводники $\mathrm{A}^{\mathrm{II}} \mathrm{B}^{\mathrm{VI}}$, легирование, полупроводниковые структуры, полиметилметакрилат, композиты, фотолюминесценция.

DOI: 10.21883/PJTF.2021.16.51330.18741

Исследования наноразмерных полупроводниковых структур являются актуальными [1-4]. Для них характерны фото- и электролюминесценция. Легирование полупроводниковых кристаллов ионами металлов позволяет целенаправленно формировать их энергетическую диаграмму, создавая в запрещенной зоне систему энергетических уровней.

Для структур, легированных ионами $\mathrm{Mn}^{2+}$, характерна полоса фотолюминесценции (ФЛ) в области $\sim 580 \mathrm{~nm}$, связанная с его электронными переходами ${ }^{4} T_{1} \rightarrow{ }^{6} A_{1} \quad[5,6]$. Концентрация ионов $\mathrm{Mn}^{2+}$ влияет на механизм ФЛ и ее интенсивность [7]. Востребованность легирования медью объясняется ее способностью легко встраиваться в кристаллическую решетку полупроводника-хозяина. В спектре ФЛ структур $\mathrm{ZnS}: \mathrm{Cu}$ наблюдаются полосы в синем $(\sim 400,470-480 \mathrm{~nm})$ и зеленом $(\sim 530 \mathrm{~nm})$ диапазонах. Структуры $\mathrm{CdS}: \mathrm{Cu}$ люминесцируют в области спектра $\geqslant 700 \mathrm{~nm}[6,8,9]$. В наноразмерных кристаллах ионы $\mathrm{Cu}^{2+}$ восстанавливаются до $\mathrm{Cu}^{+}[6,10]$. Механизм их внедрения в кристаллическую решетку полупроводниковой матрицы является дискуссионным [6,8-10]. При легировании полупроводниковых кристаллов ионами $L n^{3+}$ формируются изолированные центры узкополосной люминесценции $[6,11,12]$. Для ионов $\mathrm{Eu}^{3+}$ она связана с электронными переходами ${ }^{5} D_{0} \rightarrow{ }^{7} F_{J}$. Возбуждение электронных состояний $\mathrm{Ln}^{3+}$ происходит в результате собственного поглощения энергии, ее переноса из зоны проводимости и с уровней структурных дефектов.

Для получения легированных структур широко применяется коллоидный синтез [5,13]. Агрегационная устойчивость частиц поддерживается введением поверхностно-активных веществ [14], внедрением в полимерные матрицы [15]. Предлагаемый нами способ совмещает процессы синтеза наноразмерных структур и отверждения матрицы до стеклообразного состояния. Применение метода возникающих реагентов исключает введение в системы $\mathrm{H}_{2} \mathrm{~S}$ и $\mathrm{Na}_{2} \mathrm{~S}$ в качестве сульфидизаторов. Сероводород постепенно образуется при разложении тиоацетамидных комплексов металлов в процессе получения коллоидных растворов и при полимеризации мономера [16].

В предыдущих публикациях нами приведены результаты исследования ФЛ композиций, содержащих $\mathrm{ZnS}$ и $\mathrm{CdS}$, и их структуры $[17,18]$. В настоящей работе предпринята попытка послойного легирования $\mathrm{ZnS}$ и $\mathrm{CdS}$ в процессе синтеза трехслойной структуры $\mathrm{ZnS} / \mathrm{CdS} / \mathrm{ZnS}$. Выбор легирующих ионов $\mathrm{Mn}^{2+}$, $\mathrm{Cu}(\mathrm{I}, \mathrm{II})$ и $\mathrm{Eu}^{3+}$ обусловлен оптическими и магнитными свойствами получаемых композиций $[6,11,12]$. Синтез проведен последовательным введением солей металлов в метилметакрилат (MМА) по следующей методике (пример приготовления реакционной смеси, соответствующей первой схеме): одновременное растворение в ММА навесок трифторацетатов цинка и марганца, а также тиоацетамида в эквивалентном цинку количестве, нагревание раствора в течение 20 min при температуре $70^{\circ} \mathrm{C}$ (объем раствора $6 \mathrm{ml}$ ); затем введение раствора, содержащего трифторацетаты кадмия и европия, а также тиоацетамид в эквивалентном кадмию количестве $(1 \mathrm{ml})$, нагревание при тех же условиях; далее введение раствора, содержащего трифторацетаты цинка и меди, а также тиоацетамид в количестве, эквивалентном цинку (1 ml), нагревание $20 \mathrm{~min}\left(70^{\circ} \mathrm{C}\right)$. Остальные растворы готовили аналогично, прибавляя к трифторацетату цинка или кадмия трифторацетат соответствующего легирующего катиона. 


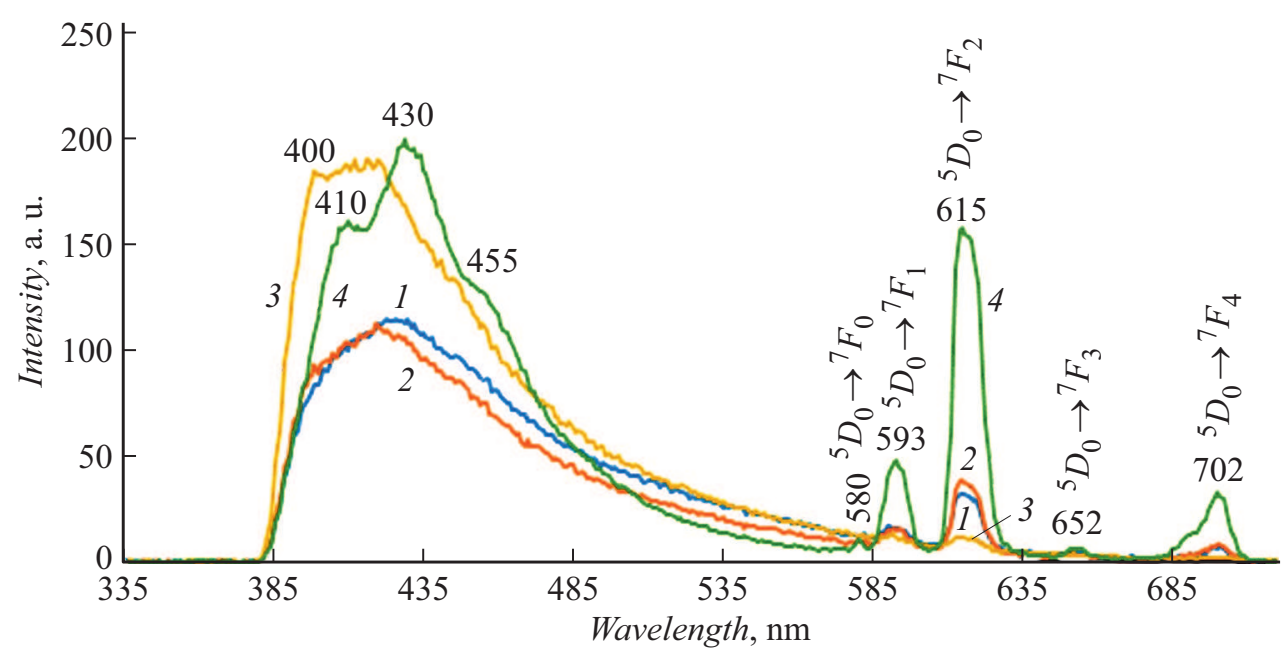

Рис. 1. Спектры ФЛ композиций ПММА/[(Zn,Cd)S:Mn,Cu,Eu] $\left(\lambda_{e x}=340 \mathrm{~nm}\right)$, соответствующих схемам синтеза ПММА/[ZnS:Mn/CdS:Eu/ZnS: $\mathrm{Cu}] \quad(1), \quad \Pi M M A /[\mathrm{ZnS}: \mathrm{Eu} / \mathrm{CdS}: \mathrm{Mn} / \mathrm{ZnS}: \mathrm{Cu}] \quad$ (2), ПMMA/[ZnS: $\mathrm{Mn} / \mathrm{CdS}: \mathrm{Cu} / \mathrm{ZnS}: \mathrm{Eu}] \quad(3)$ и ПММA/[( $\left.\mathrm{ZnS}: \mathrm{Mn} / \mathrm{CdS}: \mathrm{Cu} / \mathrm{ZnS}): \mathrm{Eu}\left(\mathrm{CF}_{3} \mathrm{COO}\right)_{3}\right](4)$.

Трифторацетаты металлов в растворе образуют комплексы с тиоацетамидом. Процесс сопровождается выходом из состава кристаллогидрата соли молекул воды. В результате гидролиза тиоацетамида образуется сероводород. Нагревание ускоряет этот процесс. Взаимодействие $\mathrm{H}_{2} \mathrm{~S}$ с солью приводит к образованию сульфидов металлов. Раствор переходит в коллоидное состояние. Образование коллоидных растворов подтверждают возникающая опалесценция и окраска растворов, соответствующая окраске образующихся сульфидов. Более подробно данный процесс рассмотрен в работах $[16,19]$.

Последовательность введения солей цинка и кадмия в растворы определялась ролью, которая отводится каждому последующему слою в многослойных структурах $[1,20]$. Каждый следующий слой сглаживает дефекты поверхности и минимизирует различия кристаллических структур слоев. Он формируется исходя из ширины запрещенной зоны полупроводника с учетом влияния размерного эффекта [20]. Учет всего комплекса факторов направлен на формирование прогнозируемой энергетической диаграммы частиц и композиций в целом. Выбранная нами последовательность введения легирующих ионов соответствовала следующим схемам: $\mathrm{ZnS}: \mathrm{Mn} / \mathrm{CdS}: \mathrm{Eu} / \mathrm{ZnS}: \mathrm{Cu}$ (композиция 1), $\mathrm{ZnS}: \mathrm{Eu} / \mathrm{CdS}: \mathrm{Mn} / \mathrm{ZnS}: \mathrm{Cu}$ (композиция 2), $\mathrm{ZnS}: \mathrm{Mn} / \mathrm{CdS}: \mathrm{Cu} / \mathrm{ZnS}: \mathrm{Eu}$ (композиция 3). Концентрация солей цинка и кадмия в конечном растворе составляла $3.0 \cdot 10^{-3} \mathrm{~mol} / \mathrm{l}$. В сумме она равна $9.0 \cdot 10^{-3} \mathrm{~mol} / \mathrm{l}$. Концентрации ионов $\mathrm{Mn}^{2+}$ и $\mathrm{Cu}(\mathrm{I}, \mathrm{II})$ во всех растворах составляли по $5.0 \cdot 10^{-4} \mathrm{~mol} / 1$. Концентрация ионов $\mathrm{Eu}^{3+}$ была равна $1.0 \cdot 10^{-3} \mathrm{~mol} / \mathrm{l}$.

По второй методике раствор соли европия вводился в реакционную смесь на последней стадии ее приготовления после выполнения всех процедур, описанных в приведенном выше примере. Концентрация трифторацетата европия в данном случае была равна $1.0 \cdot 10^{-2} \mathrm{~mol} / \mathrm{l}$. Она превышала концентрацию солей, образующих матрицу. Соль европия распределялась в полимерной матрице. Закрепляясь на поверхности частиц полупроводника, европиевые комплексы связывали полупроводниковые частицы с матрицей. Последовательность введения легирующих компонентов в этом синтезе соответствует записи $(\mathrm{ZnS}: \mathrm{Mn} / \mathrm{CdS}: \mathrm{Cu} / \mathrm{ZnS}): \mathrm{Eu}\left(\mathrm{CF}_{3} \mathrm{COO}\right)_{3}$ (композиция 4).

Для инициирования полимеризации в растворы вносили перекись бензоила (0.10 mass\% от MMA) и нагревали при температуре $70-80^{\circ} \mathrm{C}$ до перехода в стеклообразное состояние. Общее время синтеза $24 \mathrm{~h}$. Окраска полимерных „стекол“ зависела от последовательности введения веществ в реакционную смесь. Она была бесцветной, светлой желто-зеленой („канареечной“), соответствующей окраске $\mathrm{CdS}$, или цвета прозрачной бирюзы, что соответствовало окраске ионов $\mathrm{Cu}^{+}$. Светопропускание композиций при длинах волн > $450 \mathrm{~nm}$ превышало 90\% (до $5 \mathrm{~mm}$ ). ФЛ композиций исследована по методикам $[16,17]$ на спектрофлуориметре Shimadzu RF-5301PC. На основе изменений в спектрах высказаны предположения о структуре частиц и влиянии легирующих ионов на ФЛ композиций.

В спектрах ФЛ композиций (рис. $1, \lambda_{e x}=340 \mathrm{~nm}$ ) в диапазоне 380-580 nm зарегистрирована сложная полоса рекомбинационной люминесценции $\mathrm{ZnS}$ и структур $\mathrm{ZnS}: \mathrm{Mn}[5,6]$. В коротковолновой части $(<500 \mathrm{~nm})$ она накладывалась на слабую полосу ФЛ полимерной матрицы. В присутствии $\mathrm{CdS}$ полоса ФЛ полимерной матрицы не проявлялась. Ее отсутствие объясняется переносом энергии с возбужденных уровней соединений матрицы на уровни в структуре $\mathrm{CdS}$. Это подтверждается перекрыванием полос ФЛ матрицы и возбуждения ФЛ CdS. Перенос энергии на уровни $\mathrm{ZnS}$ не зарегистрирован. Его отсутствие объясняется энергетически близким положе- 


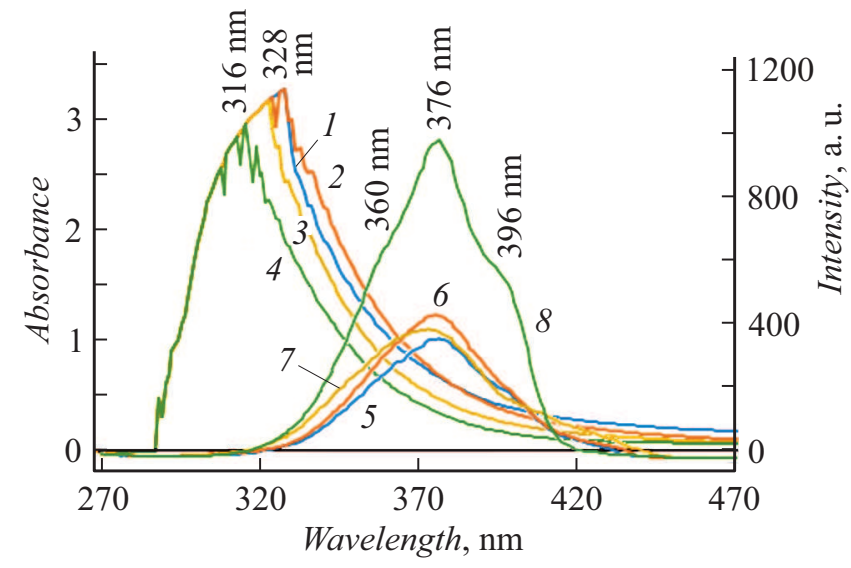

Pис. 2. Спектры поглощения $(1-4)$ и возбуждения ФЛ, зарегистрированные для излучения с длиной волны $430 \mathrm{~nm}(5-8)$, композиций ПММА/[( $\mathrm{Zn}, \mathrm{Cd}) \mathrm{S}: \mathrm{Mn}, \mathrm{Cu}, \mathrm{Eu}]$, соответствующих схемам синтеза ПММА/[ZnS:Mn/CdS:Eu/ZnS: Cu] $(1,5)$, ПММА / [ ZnS: $\mathrm{Eu} / \mathrm{CdS}: \mathrm{Mn} / \mathrm{ZnS}: \mathrm{Cu}](2,6)$,

ПММА / $[\mathrm{ZnS}: \mathrm{Mn} / \mathrm{CdS}: \mathrm{Cu} / \mathrm{ZnS}: \mathrm{Eu}](3,7)$

и ПММА / $\left[(\mathrm{ZnS}: \mathrm{Mn} / \mathrm{CdS}: \mathrm{Cu} / \mathrm{ZnS}): \mathrm{Eu}\left(\mathrm{CF}_{3} \mathrm{COO}\right)_{3}\right] \quad(4,8)$.

нием метастабильных уровней соединений полимерной матрицы с уровнями энергии в структуре $\mathrm{ZnS}$.

При длинах волн > $580 \mathrm{~nm}$ в спектрах ФЛ (рис. 1, $\lambda_{e x}=340 \mathrm{~nm}$ ) зарегистрированы узкие полосы электронных переходов ${ }^{5} D_{0} \rightarrow{ }^{7} F_{0,1,2,3,4}$ ионов $\mathrm{Eu}^{3+}$. В отличие от ПММА/ZnS/CdS [17] и ПMМA/ZnS/CdS/ZnS [18] (ПММА - полиметилметакрилат) при введении в состав композиций ионов меди практически полностью исчезает полоса ФЛ CdS в диапазоне 580-800 nm. При этом зарегистрирована полоса малой интенсивности в диапазоне $750-850 \mathrm{~nm}$ с максимумом $\sim 800 \mathrm{~nm}$, отнесенная к рекомбинационным процессам на уровнях дефектов поверхности CdS. Эффект сильного батохромного смещения полосы в структурах $\mathrm{CdS}: \mathrm{Cu}(\mathrm{I})$ также зарегистрирован авторами [9]. Батохромное смещение и крайне низкая интенсивность полосы объясняются „залечиванием“ люминесцирующих центров на поверхности $\mathrm{CdS}$ слоем $\mathrm{ZnS}$ и увеличением вероятности безызлучательной дезактивации возбуждения при усложнении энергетической диаграммы после легирования. Близкий контур спектров композиций 1 и 2 (спектры 1 и 2 на рис. 1) подчеркивает роль внешнего слоя $\mathrm{ZnS}$ в формировании ФЛ. Введение ионов $\mathrm{Eu}^{3+}$ приводит к изменению контура полосы ФЛ в области 385-500 nm (спектр 3 на рис. 1) из-за изменения дефектности $\mathrm{ZnS}$. В области 580-630 nm отмечено перераспределение интенсивностей спектральных полос, связанных с переходами электронов ${ }^{5} D_{0} \rightarrow{ }^{7} F_{1}$ и ${ }^{5} D_{0} \rightarrow{ }^{7} F_{2}$ в ионах $\mathrm{Eu}^{3+}$. Уменьшение интенсивности полосы ${ }^{5} D_{0} \rightarrow{ }^{7} F_{2}$ в спектре композции 3 относительно таковой для спектров композиций 1 и 2 (спектры 1-3 на рис. 1) соответствует увеличению симметрии европиевых центров в слое $\mathrm{ZnS}$. Введение соли европия в раствор на последней стадии синтеза (вторая методика) приводит к значительному увеличению интенсивности полос ФЛ $\mathrm{Eu}^{3+}$ (спектр 4 на рис. 1). Полоса рекомбинационной люминесценции приобретает структуру. Ее пиковая интенсивность практически не изменяется. Наличие структуры полосы объясняем образованием дефектов на поверхности внешнего слоя $\mathrm{ZnS}$ ионами $\mathrm{Eu}^{3+}$, связанными в комплексы с компонентами матрицы. Они имеют возможность получать дополнительную энергию в результате ее переноса с уровней хромофорных групп лигандов.

В спектрах возбуждения ФЛ композиций (спектры $5-8$ на рис. $\left.2, \lambda_{L}=430 \mathrm{~nm}\right)$ зарегистрированы полосы в интервале длин волн $320-420 \mathrm{~nm}$. Полосы соответствуют наноразмерным частицам $\mathrm{ZnS}$ [17]. Они перекрываются с полосами в спектрах поглощения композиций в их длинноволновой части (спектры $1-4$ на рис. 2). Наблюдается гипсохромное смещение максимума полос от композиции 1 к композиции 4. Для композиции 4 положение полосы приближается к области фундаментального поглощения $\mathrm{ZnS}$. Для частиц диаметром $<5 \mathrm{~nm}$ край полосы поглощения находится в области $320 \mathrm{~nm}$ [21]. Батохромное смещение края полос поглощения относительно $320 \mathrm{~nm}$ в область 340-380 nm (спектры $1-4$ на рис. 2) объясняется увеличением размера частиц и электронными переходами на уровни дефектов структуры. Исходя из спектров можно предположить, что возбуждение ФЛ происходит в результате перехода электронов на уровни дефектов структуры и собственные уровни легирующих ионов в запрещенной зоне полупроводника. Увеличение интенсивности и появление структуры полосы в спектре возбуждения композиции 4 (рис. 2) объясняется образованием ионами $\mathrm{Eu}^{3+}$ дефектов на поверхности частиц и переносом энергии в результате их связывания в комплексы с компонентами матрицы. Эти особенности вызваны методикой синтеза (вторая методика) и большей концентрацией соли европия $\left(C_{\mathrm{Eu}}=1.0 \cdot 10^{-2} \mathrm{~mol} / \mathrm{l}\right)$. Плечо с максимумом $\sim 396 \mathrm{~nm}$ на ниспадающей ветви полосы возбуждения (спектр 8 на рис. 2) совпадает с максимумом полосы поглощения электронного перехода ${ }^{7} F_{0} \rightarrow{ }^{5} L_{6}$ ионов $\mathrm{Eu}^{3+}$.

В спектрах возбуждения ФЛ $\left(\lambda_{L}=616 \mathrm{~nm}\right)$ зарегистрирована широкая полоса с максимумом $\sim 350 \mathrm{~nm}$ (спектры 1-4 на рис. 3). Она связана с переносом энергии с уровней полупроводниковой структуры на возбужденные уровни ионов $\mathrm{Eu}^{3+}[6,11,12]$, а также c переносом энергии с уровней хромофорных групп комплексов $\mathrm{Eu}^{3+}$. В композиции 4 эти процессы объясняют высокую интенсивность данной полосы (рис. 3). Зарегистрированы узкие полосы возбуждения, соответствующие электронным переходам ${ }^{7} F_{0} \rightarrow{ }^{5} L_{6}(395 \mathrm{~nm})$ и ${ }^{7} F_{0} \rightarrow{ }^{5} D_{2}(465 \mathrm{~nm})$ в спектрах поглощения $\mathrm{Eu}^{3+}$. В спектрах композиций $1-3$ переход ${ }^{7} F_{0} \rightarrow{ }^{5} L_{6}(395 \mathrm{~nm})$ проявляется как ступень на ниспадающей ветви широкой полосы.

В спектрах ФЛ композиций, зарегистрированных при возбуждении излучением с длиной волны $395 \mathrm{~nm}$, соответствующей электронному переходу ${ }^{7} F_{0} \rightarrow{ }^{5} L_{6}$ ионов $\mathrm{Eu}^{3+}$, присутствует широкая полоса рекомбинационной 


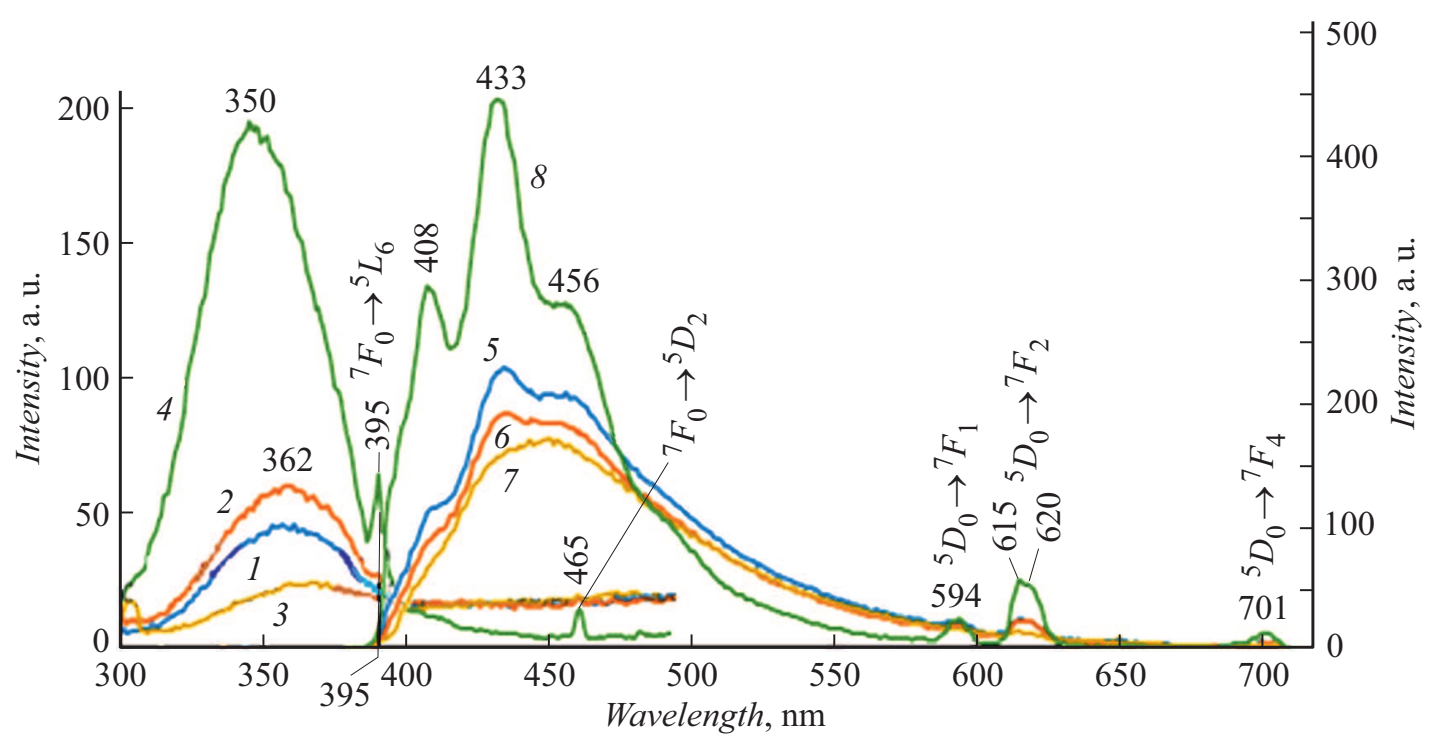

Рис. 3. Спектры возбуждения ФЛ $\left(\lambda_{L}=616 \mathrm{~nm}\right) \quad(1-4, \quad$ левая $\quad$ ось $) \quad$ и $\quad$ спектры $\left(\lambda_{e x}=395 \mathrm{~nm}\right) \quad(5-8, \quad$ правая ось $) \quad$ композиций ПMMA/[(Zn,Cd)S:Mn, Cu,Еu], соответствующих схемам синтеза ПMМА/[ZnS:Mn/CdS:Eu/ZnS:Cu] (1,5), ПMMA/[ZnS: $\mathrm{Eu} / \mathrm{CdS}: \mathrm{Mn} / \mathrm{ZnS}: \mathrm{Cu}] \quad(2,6), \quad \Pi M M A /[\mathrm{ZnS}: \mathrm{Mn} / \mathrm{CdS}: \mathrm{Cu} / \mathrm{ZnS}: \mathrm{Eu}] \quad(3,7)$ и ПММА/[(ZnS: $\left.\mathrm{Mn} / \mathrm{CdS}: \mathrm{Cu} / \mathrm{ZnS}): \mathrm{Eu}\left(\mathrm{CF}_{3} \mathrm{COO}\right)_{3}\right](4,8)$.

люминесценции при длинах волн больше $395 \mathrm{~nm}$, а также узкие полосы электронных переходов ${ }^{5} D_{0} \rightarrow{ }^{7} F_{1,2,4}$ ионов $\mathrm{Eu}^{3+}$ с максимумами $594 \mathrm{~nm}\left({ }^{5} D_{0} \rightarrow{ }^{7} F_{1}\right), 615$ и $620 \mathrm{~nm}\left({ }^{5} D_{0} \rightarrow{ }^{7} F_{2}\right), 701 \mathrm{~nm}\left({ }^{5} D_{0} \rightarrow{ }^{7} F_{4}\right)$ (спектры $5-8$ на рис. 3 ). Появление двух типов полос ФЛ объясняется перекрыванием полос поглощения полупроводниковой структуры с ${ }^{7} F_{0} \rightarrow{ }^{5} L_{6}$ полосой поглощения ионов $\mathrm{Eu}^{3+}$. Полоса рекомбинационной ФЛ композиции 4 (рис. 3) имеет выраженную структуру, которая связана с дефектностью частиц полупроводника.

Таким образом, ФЛ композиции ПММА/[(Zn,Cd)S:Mn,Cu,Eu] связана с процессами во внешнем слое $\mathrm{ZnS}$ и на поверхности частиц. Роль легирующих ионов состоит в формировании структурных дефектов с соответствующими им уровнями энергии. ФЛ возникает в результате рекомбинационных процессов на этих уровнях. Она возбуждается переходами электронов из валентной зоны. Люминесценция $\mathrm{CdS}$ затухает при введении в композиции ионов меди. Узкополосная люминесценция связана с уровнями энергии ионов $\mathrm{Eu}^{3+}$. Ее возбуждение происходит при собственном поглощении энергии ионами $\mathrm{Eu}^{3+}$, переносе энергии на их уровни с уровней полупроводниковой структуры и хромофорных групп лигандов. Полученные результаты подтверждают заявленный синтез и показывают влияние легирующих ионов на ФЛ полупроводниковых структур и композиций в целом.

\section{Конфликт интересов}

Авторы заявляют, что у них нет конфликта интересов.

\section{Список литературы}

[1] P. Melinon, S. Begin-Colin, J.L. Duvail, F. Gauffre, N.H. Boime, G. Ledoux, J. Plain, P. Reiss, F. Silly, B. WarotFonrose, Phys. Rep., 543, 163 (2014). http://dx.doi.org/10.1016/j.physrep.2014.05.003

[2] H. Kumar, A. Kumari, R.R. Singh, Opt. Mater., 69, 23 (2017). http://dx.doi.org/10.1016/j.optmat.2017.04.009

[3] X. Tong, X.-T. Kong, C. Wang, Y. Zhou, F. Navarro-Pardo, D. Barba, D. Ma, S. Sun, A.O. Govorov, H. Zhao, Z.M. Wang, F. Rosei, Adv. Sci., 5 (8), 1800656 (2018). DOI: $10.1002 /$ advs.201800656

[4] G.S. Selopal, H. Zhao, G. Liu, H. Zhang, X. Tong, K. Wang, J. Tang, X. Sun, S. Sun, F. Vidal, Y. Wang, Z.M. Wang, F. Rosei, Nano Energy, 55, 377 (2019). https://doi.org/10.1016/j.nanoen.2018.11.001

[5] M. Kuzmanović, D.K. Bozanić, D. Milivojević, D.M. Ćulafić, S. Stanković, C. Ballesteros, J. Gonzalez-Benito, RSC Adv., 7 (84), 53422 (2017). https://doi.org/10.1039/C7RA11011A

[6] Д.О. Сагдеев, Оптические и магнитные свойства квантовых точек халькогенидов кадмия и иинка, легированных ионами марганща, меди, европия и гадолиния, канд. дис. (КНИИТУ, Казань, 2019).

[7] R. Nasser, H. Elhouichet, M. Férid, Appl. Surf. Sci., 351, 1122 (2015). DOI: 10.1016/j.apsusc.2015.06.096

[8] S. Muruganandam, G. Anbalagan, G. Murugadoss, Optik, 130, 82 (2017). DOI: 10.1016/j.ijleo.2016.11.053

[9] F. Zhang, X.-W. He, W.-Y. Li, Y.-K. Zhang, J. Mater. Chem., 22 (41), 22250 (2012). DOI: 10.1039/c2jm33560c

[10] B.B. Srivastava, S. Jana, N. Pradhan, J. Am. Chem. Soc., 133 (4), 1007 (2011). DOI: 10.1021/ja1089809

[11] Z. Liang, J. Mu, L. Han, H. Yu, J. Nanomater., 2015, 519303 (2015). https://doi.org/10.1155/2015/519303

[12] Q. Chen, J. Song, Ch. Zhou, Q. Pang, L. Zhou, Mater. Sci. Semicond. Process., 46, 53 (2016). https://doi.org/10.1016/j.mssp.2016.02.005 
[13] S. Muruganandam, G. Anbalagan, G. Murugadoss, Ind. J. Phys., 89 (8), 835 (2015).

DOI: $10.1007 / \mathrm{s} 12648-015-0650-7$

[14] R.N. Bhargava, D. Gallagher, X. Hong, A. Nurmikko, Phys. Rev. Lett., 72 (3), 416 (1994).

[15] R.M. Abozaid, Z.Ž. Lazarević, I. Radović, M. Gilić, D. Šević, M.S. Rabasović, I. Radović, Opt. Mater., 92, 405 (2019). https://doi.org/10.1016/j.optmat.2019.05.012

[16] А.А. Исаева, В.П. Смагин, В.А. Зяблицкая, ЖНХ, 64 (1), 108 (2019). DOI: 10.1134/S0044457X19010112

[17] А.А. Исаева, В.П. Смагин, ЖНХ, 64 (10), 1020 (2019). DOI: $10.1134 / \mathrm{S} 0044457 \mathrm{X} 19100064$

[18] А.А. Исаева, В.П. Смагин, Изв. вузов. Химия и хим. технология, 63 (11), 82 (2020). DOI: $10.6060 /$ ivkkt.20206311.6231

[19] В.П. Смагин, Н.С. Еремина, А.А. Исаева, ЖНХ, 62 (1), 130 (2017). DOI: 10.7868/S0044457X17010226

[20] E. Ramya, M.V. Rao, D.N. Rao, Physica E, 107, 24 (2019). https://doi.org/10.1016/j.physe.2018.11.010

[21] В.П. Смагин, А.А. Исаева, Н.С. Еремина, А.А. Бирюков, ЖПХ, 88 (6), 924 (2015).

DOI: $10.1134 / \mathrm{S} 1070427215060208$ 